\title{
Sodium alginate adhesives as binders in wood fibers/textile waste fibers biocomposites for building insulation
}

\author{
Clément Lacoste $^{\mathrm{a}, *}$, Roland El Hage ${ }^{\mathrm{b}}$, Anne Bergeret ${ }^{\mathrm{a}}$, Stéphane Corn ${ }^{\mathrm{a}}$, Patrick Lacroix ${ }^{\mathrm{c}}$ \\ ${ }^{\text {a } C e n t r e ~ d e s ~ M a t e ́ r i a u x ~ d e s ~ M i n e s ~ d ' A l e ̀ s ~(C 2 M A), ~ E c o l e ~ d e s ~ M i n e s ~ d ' A l e ̀ s, ~} 6$ Avenue de Clavières, F-30119 Alès Cedex, France \\ ${ }^{\mathrm{b}}$ Laboratoire de Chimie-Physique des Matériaux (LCPM), Université Libanaise, Faculté des Sciences II, Fanar, Lebanon \\ ${ }^{\mathrm{c}}$ Greenpile, 30 rue Pierre Brasseur, 77100 Meaux, France
}

\section{A B S T R A C T}

Alginate derived from seaweed is a natural polysaccharide able to form stable gel through carbohydrate functional groups largely used in the food and pharmaceutical industry. This article deals with the use of sodium alginate as an adhesive binder for wood fibres/textile waste fibres biocomposites. Several aldehyde-based crosslinking agents (glyoxal, glutaraldehyde) were compared for various wood/textile waste ratios (100/0, 50/ $50,60 / 40,70 / 30$ and 0/100 in weight). The fully biomass derived composites whose properties are herewith described satisfy most of the appropriate requirements for building materials. They are insulating with a thermal conductivity in the range $0.078-0.089 \mathrm{~W} / \mathrm{m} / \mathrm{K}$ for an average density in the range $308-333 \mathrm{~kg} / \mathrm{m} 3$ according to the biocomposite considered. They are semi-rigid with a maximal mechanical strength of $0.84 \mathrm{MPa}$ under bending and 0.44 MPa under compression for $60 / 40 \mathrm{w} / \mathrm{w}$ wood/textile waste biocomposites with a glutaraldehyde crosslinking agent.

Keywords:

Sodium alginate

Wood fibres

Textile waste fibres

Biocomposite

Insulation materials

\section{Introduction}

The major consumption of primary energy in the world is attributable to buildings, in particular for heating, which are also responsible of about a third of the greenhouse gas emissions on Earth. In the recent past, efforts have been made to reduce total energy consumption of buildings to avoid energy wastage by more efficient insulation systems. Unfortunately, building insulation materials produced from petrochemicals (polystyrene, polyurethane) or from mineral sources processed with high energy consumptions (glass and rock wool) are ubiquitous. Synthetic polymers, which are non-renewable in a short term, consist of residual chemicals and volatile organic compounds (VOCs) toxic for health and environment and their reuse and recycling are quite difficult, to such an extent that it is preferred for incineration (Asdrubali, D'Alessandro, \& Schiavoni, 2015).

Many studies have been carried out with the goal of developing biobased composites with at least comparable performance to traditional building materials but with a lower environmental impact. The incorporation of natural fibers in petrochemical-based thermoplastics and thermoset matrixes were extensively studied, albeit over $80 \%$ of the market of natural fibers composite is dominated by traditional petroleum based matrices such as polyethylene, polypropylene (Faruk, Bledzki, Fink, \& Sain, 2012). The development of low-cost and fully bio- based natural fibers composites (NFC) based on constituents obtained from natural and sustainable sources is thus considered as of great importance.

Various strategies have been proposed in the last decade to combine biosourced binders and natural fibers such as lignin, tannins, proteins, or oils. Lignin is biosourced and largely available throughout the world but need to be activated to be effective with a thermal or chemical treatment which makes its use complex (Ghaffar \& Fan, 2014). In the same way, tannins are natural polyphenols widely present in nature but only condensed tannins have a sufficient chemical reactivity to be potentially developed (Pizzi, Scharfetter, \& Kes, 1981). Tannins can successfully be used as binder for non-woven natural fibers (Pizzi, Kueny, \& Lecoanet, 2011), wood particleboards (Pizzi, 1982; Pizzi et al., 1981) and natural fibers such as flax or hemp (Nicollin, Kueny, Toniazzo, \& Pizzi, 2012; Pizzi et al., 2009). However, tannins extraction is expensive and water costly, limiting its industrial development. Bioresin derived from vegetal protein such as soja (Kumar, Choudhary, Mishra, Varma, \& Mattiason, 2002) or sunflower cake (Evon, Vandenbossche, Pontalier, \& Rigal, 2014) have also been used in NFC but their low water resistance and the high cost of the oleaginous part purification have limited their applications.

Marine biomass is an interesting source of natural polysaccharide precursors such as chitosane, recently introduced in building insulation

\footnotetext{
* Corresponding author

E-mail address: clement.lacoste@mines-ales.fr (C. Lacoste).
} 
(a)

M

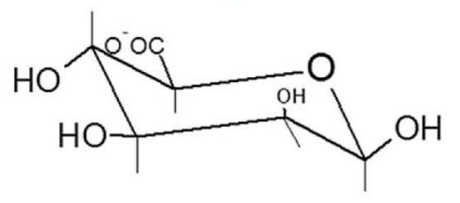

$\beta$ D Mannuronate
G<smiles>CC1(O)CC2CC1(C(=O)[O-])OC(C)(O)C2(C)O</smiles>

$\alpha$ L Guluronate

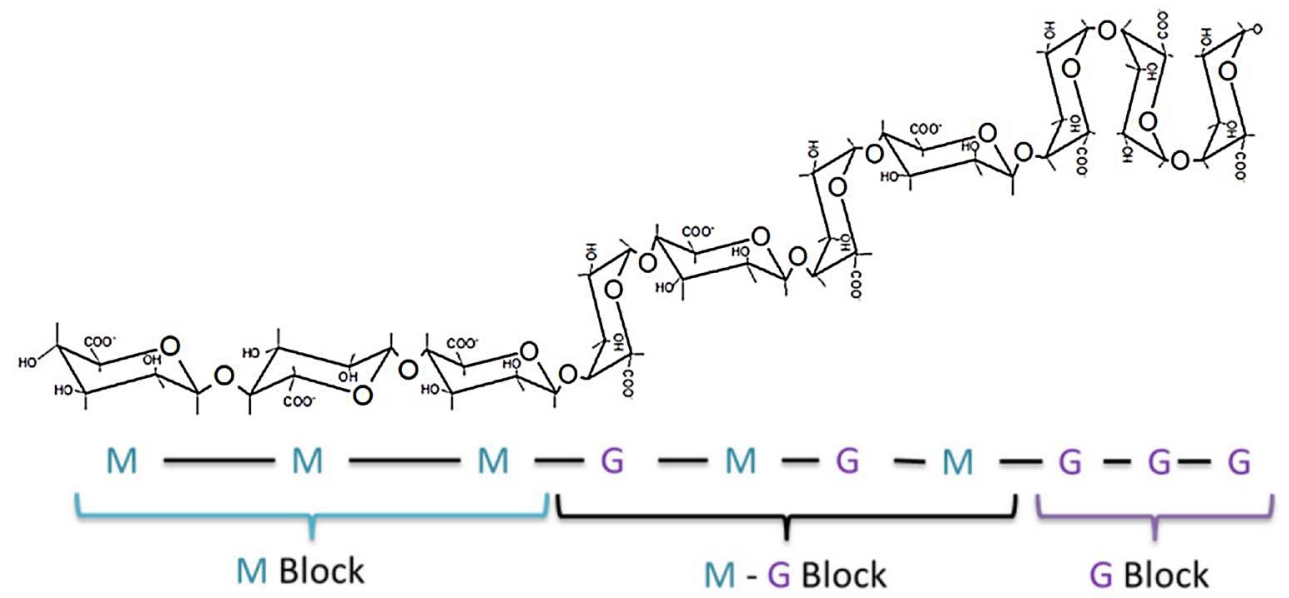

(b)

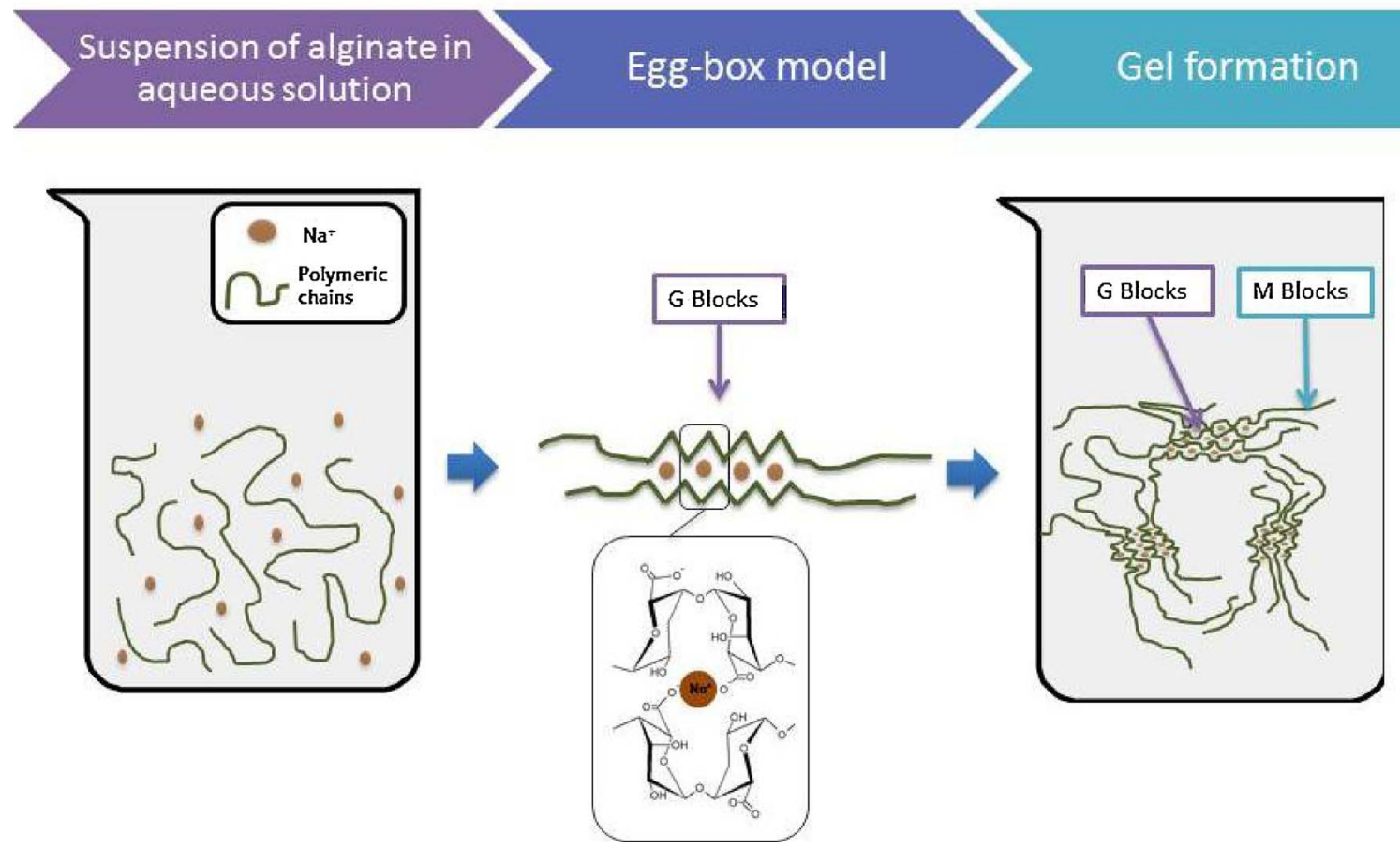

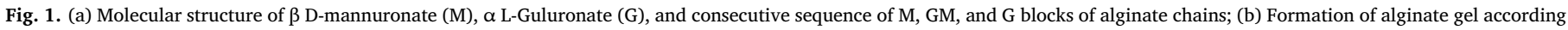
to the egg-box model. 
Table 1

Designation of the composite samples and their corresponding formulations.

\begin{tabular}{|c|c|c|c|c|c|c|c|c|}
\hline Name & Wood fibers (g) & Recycled cotton fibers $(\mathrm{g})$ & Water (g) & Alginate (g) & Glycerol (g) & Glyoxal (g) & Glutaraldehyde (g) & Ratio dry Matrix/Fibers \\
\hline WT0/100 & - & 64 & 224 & 16 & 4 & - & - & 0.31 \\
\hline WT50/50 & 32 & 32 & 224 & 16 & 4 & - & - & 0.31 \\
\hline WT60/40 & 38.4 & 25.6 & 224 & 16 & 4 & - & - & 0.31 \\
\hline WT70/30 & 44.8 & 19.2 & 224 & 16 & 4 & - & - & 0.31 \\
\hline WT100/0 & 64 & - & 224 & 16 & 4 & - & - & 0.31 \\
\hline WT60/40G & 38.4 & 25.6 & 224 & 16 & 4 & 8 & - & 0.31 \\
\hline WT60/40Gu & 38.4 & $25 . .6$ & 224 & 16 & 4 & - & 8 & 0.31 \\
\hline
\end{tabular}

panels. Mati-Baouche et al. (2014) have developed an insulating lightweight composite (density between $150-200 \mathrm{~kg} / \mathrm{m}^{3}$ ) made with chitosan and sunflower's stalks particles which allows competitive thermal (conductivity of $0.056 \mathrm{~W} / \mathrm{m} / \mathrm{K}$ ) and mechanical performance (maximum stress of $2 \mathrm{MPa}$ under compression). Alginate polysaccharides derived from brown algae have never been used in such application to our knowledge. Commercially, alginates production reaches a total volume of $40000 \mathrm{t}$ per year (Quignard, Valentin, \& Di Renzo, 2008; Rinaudo, 2008). Their chemical structure contains linear blocks of (1- > 4) $\beta$-D-mannuronic acid (M) and $\alpha$-L-guluronic acid (G) monomers sequenced alternatively with consecutive $\mathrm{G}$ residues, $\mathrm{M}$ residues, and GM residues (Fig. 1a). One of the remarkable properties of alginate is its ability to form a gel through a complex formation between a divalent (or trivalent) cation (like $\mathrm{Ca}^{2+}, \mathrm{Al}^{3+}, \mathrm{Fe}^{3+}$ ) and $\mathrm{G}$ blocks representing by the egg-box model (Mookhoek, Fischer, \& Van Der Swaag, 2012) (Fig. 1b). The stability and the stiffness of the gel are determined by the length and the proportion of the G blocks (Rinaudo, 2008).

Alginates are soluble in cold water and do not need a heating and cooling cycle to form gel. They are particularly biodegradable, biocompatible, bioactive anionic polysaccharide, and they have low toxicity and low cost. They are widely used in the food and textile industries as thickeners, stabilizers, gel-formers, or film-formers (Zia, Zia, Zuber, Rehman, \& Ahmad, 2015). Alginate appears then as a promising biopolymer with adhesive properties.

The most widely known natural-organic fillers are wood floor and fibers. Wood fibers are produced by thermo-mechanical processes on wood waste and are widely used because of their low cost and their good mechanical properties La Mantia and Morreale (2011). In accordance with the principle of sustainability, the use of recycled fibers could also play a positive role onto the environmental impacts by reducing the use of virgin material and the disposal in landfill. In Europe, the recovery of large quantities of textiles wastes and products are urgently needed. Textile recycling is progressively growing and provides cotton fibers highly appreciated by manufacturers to produce efficient thermal insulation panels (Asdrubali et al., 2015). From this finding, cotton recycled fibers is used in this work to substitute a part of the wood fibers (Binici, Eken, Dolaz, Aksogan, \& Kara, 2014).

There is a need to develop fully eco-friendly multifunctional composites produced from new polymers, taken neither from food, nor from natural materials, but instead from by-products from agricultural, forestry, husbandry and marine activities. The purpose of this paper is to show the potential of using a sodium alginate as an adhesive thermoset binder for an alternative biocomposite associating wood fibres and recycled waste textile fibers (Lacroix, Bergeret, Corn, Lacoste, \& El Hage, 2016). First, the physico-chemical behavior of the alginate binder was studied followed by the formulation and the fabrication of wood fibers/ recycled textile composites. The thermal and mechanical properties of these composites were then characterized.

\section{Materials and methods}

\subsection{Materials}

To reinforce the composite material, wood fibers (W) (Actis, France) and textile waste $(\mathrm{T})$ from recycled jeans, namely Métisse ${ }^{\circledR}$ (Le Relais, France) were used as received. A commercial sodium alginate, provided by Cargill ${ }^{\mathrm{TM}}$ under the trademark Cecalgum ${ }^{\circledast}$ MLG N7, was used as an adhesive binder. Alginate was extracted from brown seaweed collected in Iroise sea (France) and consists of a fine water soluble white powder $(<100 \mu \mathrm{m})$ containing sodium alginate $(80 \%)$, calcium sulfate $(15 \%)$, and a low percentage of diatomaceous Earth $(3 \%)$ and tetrasodium diphosphate $(2 \%)$ with a gel setting time given at $6.5 \mathrm{~min}$. Glyoxal and glutaraldehyde were purchased from Sigma-Aldrich and used as crosslinking agent. Glycerol was provided by ChemLab (Belgium), and used as plasticizer. Formaldehyde (provided by Sigma-Aldrich) was used as a reference compared to glyoxal and glutaraldehyde in thermal reactivity study (see section Results and Discussion §1).

\subsection{Biocomposite processing}

A homogeneous mixture combining wood fibers and recycled cotton fibers was processed as followed. Wood and cotton fibers are introduced per about $10 \mathrm{~g}$ batch in a rigid bucket to obtain the desired amount of fibers (Table 1).

The bucket is then moving around a rotation axis angled at $45^{\circ}$ from the ground at $40 \mathrm{rpm}$ during $5 \mathrm{~min}$. The fibers are then mixed with a stirring blade, rotating in the opposite direction of the bucket, at $40 \mathrm{rpm}$ for $5 \mathrm{~min}$.

The alginate based solution preparation involved three steps: (i) preparation of a glycerol/water solution, (ii) introduction of the crosslinker $(8 \% \mathrm{w} / \mathrm{w})$, and (iii) introduction of the sodium alginate under continuous stirring at $200 \mathrm{rpm}$. When all the components were added, the final solution was stirred $2 \mathrm{~min}$.

The fibers previously prepared are then progressively soaked by the alginate-based solution and the wet fibers were stirred $2 \mathrm{~min}$ at $20 \mathrm{rpm}$. The wet fibers are put into a metallic mold of dimensions $160 \times 40 \times 40 \mathrm{~mm}^{3}$ and squeezed at a pressure of 50 bars with a Darragon thermocompression set up (HydroMeca, France) and left at $70{ }^{\circ} \mathrm{C}$ for $2 \mathrm{~h}$. The samples were then stored 10 days in a climate room at $20^{\circ} \mathrm{C}$ and $50 \%$ relative humidity. After reaching the mass equilibrium, 2 samples of every formulation were put in a ventilated oven at $105^{\circ} \mathrm{C}$ during $24 \mathrm{~h}$. The moisture content was measured with the following equation:

$H(\%)=\frac{w_{f}-w_{i}}{w_{f}}$

Where $\mathrm{w}_{\mathrm{f}}$ is the weight of the sample after moisture drying and $\mathrm{w}_{\mathrm{i}}$ the weight of the sample at mass equilibrium stored at $20^{\circ} \mathrm{C}$ and $50 \%$ relative humidity.

Fig. 2 shows pictures of different manufactured biocomposite samples. The different formulations tested in this work are reported in Table 1. 

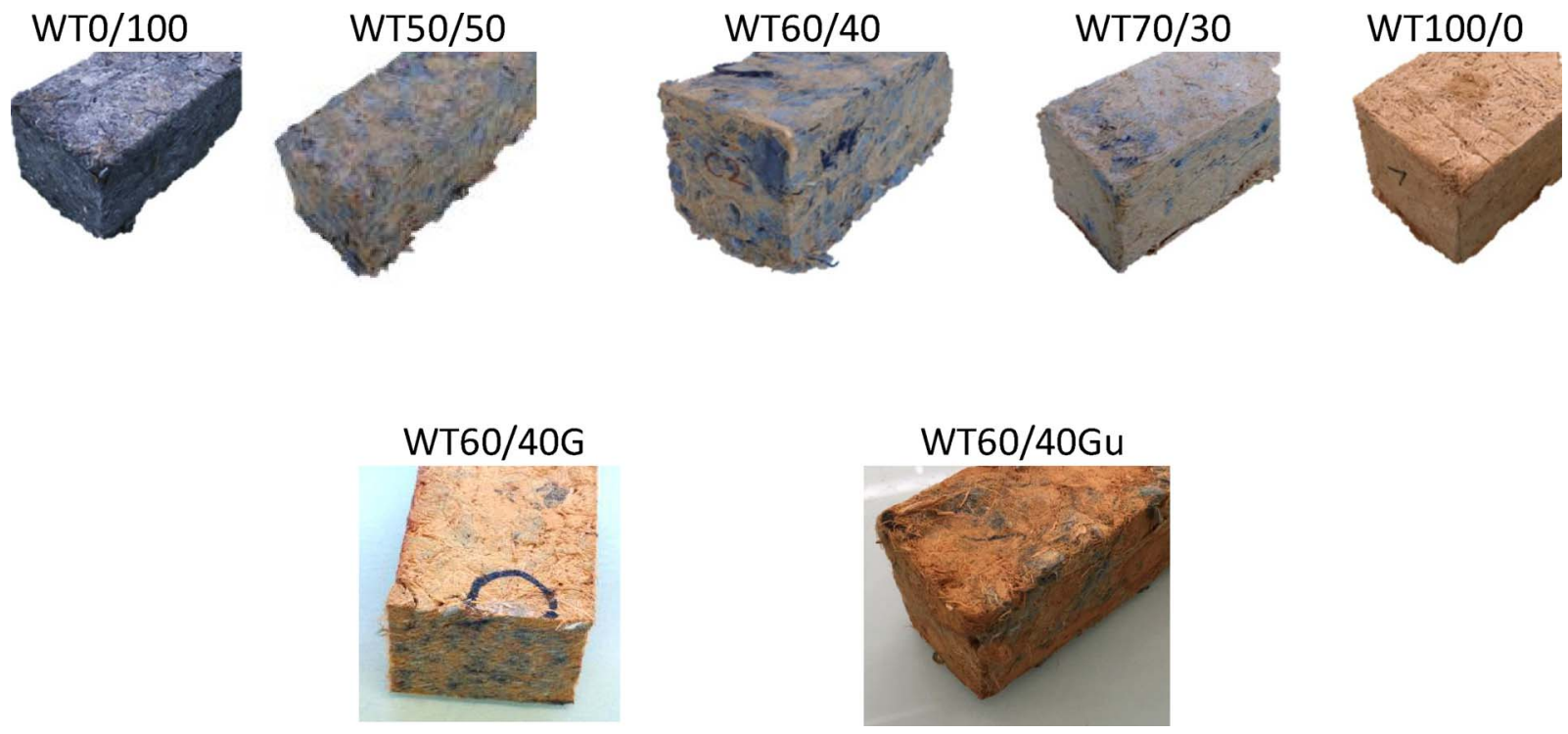

Fig. 2. Pictures of different processed biocomposites.

\section{Methods for materials characterization}

\subsection{Thermal properties}

3.1.1. Thermal properties of the alginate-based adhesives: gel time, crosslinking, thermal stability

The gel time was measured by taking $5 \mathrm{~g}$ of the sodium alginate water solution soaked into a water bath at $100^{\circ} \mathrm{C}$ under continuous stirring. The measure was made in triplicate for each sample.

The influence of crosslinker agent is studied through differential scanning calorimetry (DSC) experiments. DSC measurements were performed on a Perkin Elmer Diamond operating under a constant flow of nitrogen $\left(30 \mathrm{~mL} \mathrm{~min}^{-1}\right.$ ). Samples were weighed (around $15 \mathrm{mg}$ ) into aluminum crucibles. Analysis in comparison to a blank crucible was performed using a temperature profile (ramp rate was $10^{\circ} \mathrm{C} \mathrm{min}^{-1}$ ) from $0{ }^{\circ} \mathrm{C}$ to $250{ }^{\circ} \mathrm{C}$. Each measurement was done in duplicate.

3.1.2. Thermal properties of the biocomposite: conductivity, effusivity, diffusivity

Thermal properties were measured with FP2C conductimeter from NeoTIM $^{\circledR}$ (France) with 3 different sensors: a hot linear wire $(50 \mathrm{~mm})$, a hot plane $\left(50 \times 50 \mathrm{~mm}^{2}\right)$ and a ring sensor (diameter $=15.0 \mathrm{~mm}$ ) for the determination of the conductivity, the effusivity and the diffusivity respectively. The thermal conductivity allows measuring the heat flow resistance throughout the material, whereas the effusivity indicates the heat flow absorption in surface, and the diffusivity gives the capacity of the material to conduct and store thermal energy.

The thermal phase difference $(\varphi)$ was calculated as follow (Eq. (2)):

$\varphi=0.023 e \times \sqrt{\alpha}$

Where $e$ is the thickness of the material that was chosen to be $0.12 \mathrm{~m}$ in our case in order to represent a realistic building envelop and $(\alpha)$ is the measured thermal diffusivity.

Moreover, the thermal capacity $\left(C_{p}\right)$ was calculated with the following Eq. (3):

$C_{p}=\beta^{2} / \lambda \cdot \rho$

Where $(\lambda)$ is the thermal conductivity, $(\beta)$ is the thermal effusivity and $(\rho)$ is the density of the material. Three specimens were tested.

\subsection{Mechanical properties}

Strain-stress curves were recorded with a ZWICK TH010 universal testing machine.

For the three point bending tests, the machine was equipped with $2,5 \mathrm{kN}$ head and the load rate was fixed at $2 \mathrm{~mm} / \mathrm{min}$. Five samples of dimensions $160 \times 40 \times 40 \mathrm{~mm}^{3}$ were placed between two supports at a distance of $120 \mathrm{~mm}$ according to the standard ASTM D790. Young's modulus is measured from the stress-strain curves between $7 \%$ and $8 \%$ of strain corresponding to the middle of the linear elastic zone. The bending resistance corresponds to the yield stress.

For the compressive tests, the machine was equipped with $10 \mathrm{kN}$ head and the load rate was fixed at $10 \mathrm{~mm} / \mathrm{min}$. Ten samples of dimensions $80 \times 40 \times 40 \mathrm{~mm}^{3}$ were compressed under a prism tool of section $40 \times 40 \mathrm{~mm}^{2}$ according to the standard ASTM D695. The pressure is applied in the same direction than the pressure of the compacting was applied to manufacture the composite. Young's modulus is measured from the stress-strain curves between $3.5 \%$ and $4 \%$ of strain corresponding to the linear elastic zone. The compression resistance, usually taken at $10 \%$ strain, is taken at $20 \%$ strain in that case because the yield stress was still not reached at $10 \%$.

\section{Results and discussion}

\subsection{Thermal properties of the alginate-based adhesive}

Fig. 3 shows the DSC thermograms of alginate aqueous solutions containing $8 \mathrm{wt} . \%$ of different aldehydes (G: Glyoxal; Gu: Glutaraldehyde; FOR: formaldehyde as a reference). It can be observed that the water departure corresponding to the endothermic peak located at around $110^{\circ} \mathrm{C}$ is function of the aldehyde used. The more compact the polymeric network, the harder the water departure. Therefore the aldehyde reactivity towards alginate could be arranged as follow: Formaldehyde $>$ Glyoxal > Glutaraldehyde, which is combined with a slight increase in onset temperature (from about $78^{\circ} \mathrm{C}$ for STD and Gu to about $94^{\circ} \mathrm{C}$ for $\mathrm{G}$ and FOR).

This result is in good agreement with gel time measurements. Indeed a decrease in gel times was observed with an increase of the aldehyde reactivity: $42 \pm 4 \mathrm{~s}$ for STD, and $38 \pm 3 \mathrm{~s}, 33 \pm 2 \mathrm{~s}$ and $24 \pm 3 \mathrm{~s}$ for $\mathrm{Gu}, \mathrm{G}$ and FOR alginate solutions respectively containing $8 \mathrm{w} \%$ of crosslinking agents. This indicates that the chain mobility is reduced simultaneously to the crosslinking of the glycosidic chains.

Yeom and Lee (1998) have observed the formation of an acetal ring and ether linkage as a result of the reaction between sodium alginate and glutaraldehyde. They also observed that the formation of a compact polymeric network is a function of the volume fraction of 


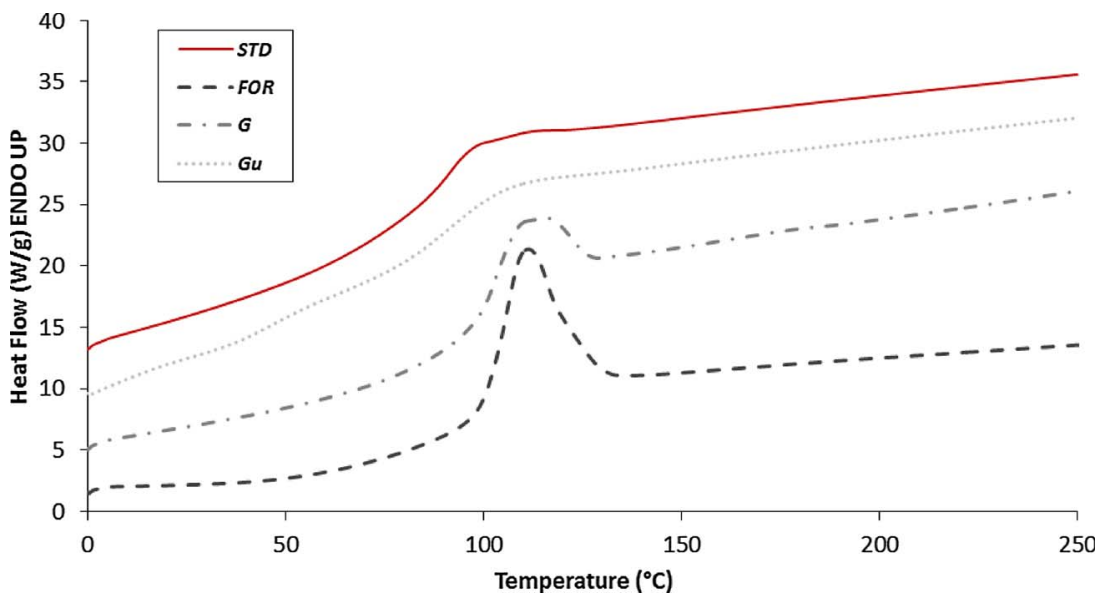

Fig. 3. DSC curves of alginate aqueous solutions without aldehyde (STD) and with different crosslinking agents (FOR : formaldehyde; G: Glyoxal; Gu : Glutaraldehyde).

Table 2

Thermal properties of alginate based biocomposites, of wood and recycled cotton fibers.

\begin{tabular}{|c|c|c|c|c|c|c|c|}
\hline Sample & $\begin{array}{l}\text { Wood fibers content } \\
\%\end{array}$ & $\begin{array}{l}\text { Density } \\
\mathrm{kg} / \mathrm{m}^{3}\end{array}$ & $\begin{array}{l}\text { Conductivity } \\
\mathrm{W} / \mathrm{m} / \mathrm{K}\end{array}$ & $\begin{array}{l}\text { Effusivity } \\
\text { W.s } \mathrm{s}^{1 / 2} / \mathrm{m}^{2} / \mathrm{K}\end{array}$ & $\begin{array}{l}\text { Diffusivity } \\
10^{-07} \mathrm{~m}^{2} / \mathrm{s}\end{array}$ & $\begin{array}{l}\text { Phase difference } \\
\mathrm{h}\end{array}$ & $\begin{array}{l}\text { Thermal capacity } \\
\mathrm{J} / \mathrm{kg} / \mathrm{K}\end{array}$ \\
\hline WT0/100 & 0 & $332.8( \pm 9.7)$ & $0.089( \pm 0.001)$ & $150( \pm 4)$ & $310( \pm 0.01)$ & 5.0 & 760 \\
\hline WT50/50 & 50 & $311.1( \pm 6.4)$ & $0.081( \pm 0.001)$ & $164( \pm 4)$ & $221( \pm 0.06)$ & 5.9 & 1174 \\
\hline WT60/40 & 60 & $308.0( \pm 4.7)$ & $0.078( \pm 0.003)$ & $172( \pm 3)$ & $236( \pm 0.17)$ & 5.7 & 1133 \\
\hline WT70/30 & 70 & $319.2( \pm 4.5)$ & $0.081( \pm 0.011)$ & $177( \pm 4)$ & $193( \pm 0.10)$ & 6.3 & 1320 \\
\hline WT100/0 & 100 & $310.6( \pm 6.9)$ & $0.082( \pm 0.030)$ & $184( \pm 3)$ & $177( \pm 0.08)$ & 6.6 & 1329 \\
\hline WT60/40G & 60 & $328.9( \pm 5.3)$ & $0.089( \pm 0.004)$ & $195( \pm 3)$ & $193( \pm 0.03)$ & 6.3 & 1402 \\
\hline WT60/40Gu & 60 & $311.3( \pm 3.6)$ & $0.082( \pm 0.007)$ & $190( \pm 4)$ & $181( \pm 0.02)$ & 6.5 & 1455 \\
\hline Wood fibers & 100 & $76.6( \pm 3.2)$ & $0.040( \pm 0.001)$ & - & $109( \pm 0.02)$ & 8.4 & 4791 \\
\hline Recycled cotton fibers & 0 & $64.6( \pm 6.1)$ & $0.036( \pm 0.002)$ & - & $759( \pm 0.06)$ & 3.2 & 734 \\
\hline
\end{tabular}

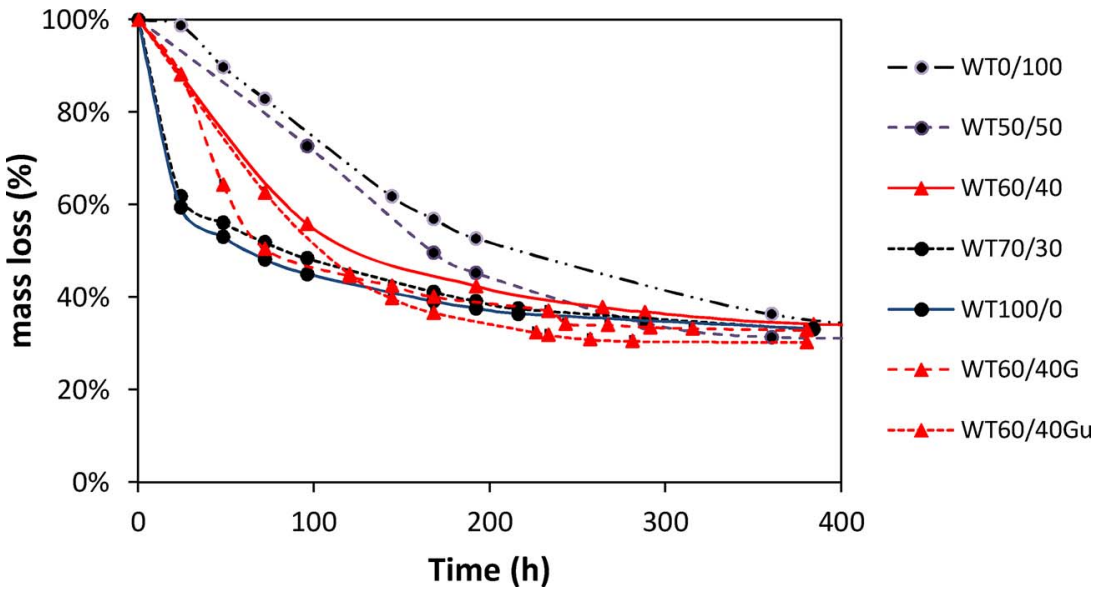

Fig. 4. Mass loss of the biocomposites as a function of time.

glutaraldehyde. Above 5\% of glutaraldehyde, Yeom and Lee (1998) observed a monofunctional reaction and bifunctional reaction of glutaraldehyde, i.e. of the two groups in glutaraldehyde molecule; either one or two group is crosslinked. With $8 \mathrm{w} \%$ of aldehyde, it can be assumed that all the aldehyde groups participate in the reaction and that only some of them are partially connected with sodium alginate chain.

Highly crosslinked polymer chains could be favorable to an improvement in the material rigidity. Although formaldehyde (FOR) appears as the best hardener to give a rigid polymeric network, it has not been employed in this study because of its admitted toxicity and a fortiori its limited industrial use.

\subsection{Characterization of the biocomposite}

\subsubsection{Study of biocomposite drying}

After being processed through thermocompression, biocomposites were left in a climate room at constant relative humidity (50\%) and temperature $\left(20^{\circ} \mathrm{C}\right)$. At this step, the average wet density of every sample was measured at $970( \pm 10) \mathrm{kg} / \mathrm{m}^{3}$. The samples, still containing a large quantity of water, were then dried by natural convection in the climate room until their mass stabilization.

The final density of the composites is in the range $308-333 \mathrm{~kg} / \mathrm{m}^{3}$ according to their formulation (Table 2). Fig. 4 shows that the equilibrium is reached after $250 \mathrm{~h}$, for all biocomposites except WT0/100 and WT50/50 that contain the highest textile contents. For these last ones, the mass equilibrium is reached at times greater than $350 \mathrm{~h}$ (about 15 days). It can be assumed that textile waste fibers are highly hydrophilic compared to wood fibers. The moisture content of composites was measured at $7.4( \pm 0.1) \%$ and the fibers ratio is then $77 \%$ on average. Therefore the drying kinetic seems to be directly a function of the textile fibers content. The more the wood content, the higher the mass loss slope. As concerns WT60/40 biocomposites (red curves on Fig. 4), 
(a)

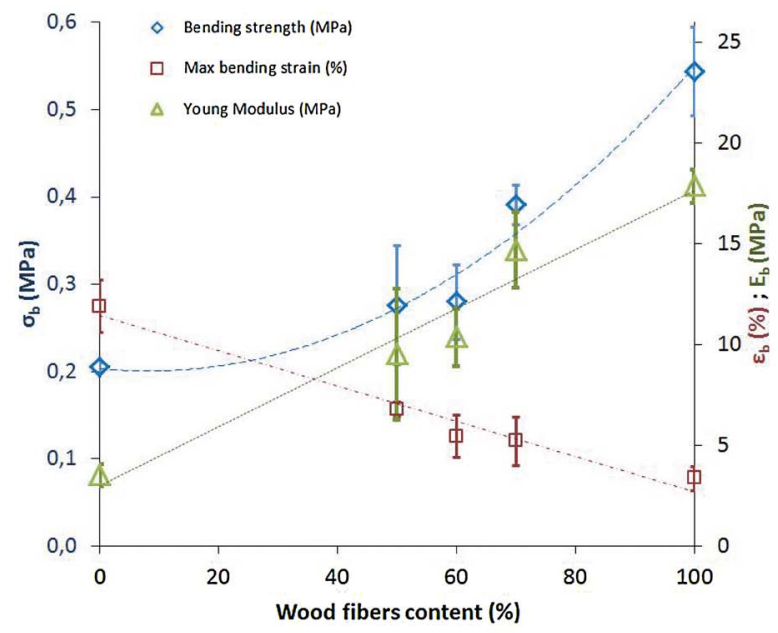

Fig. 5. Bending properties (a) of alginate-based composites as a function of the wood fibers contents and (b) of WT60/40 alginate-based biocomposites with different crosslinking agents: Young's modulus $\left(\mathrm{E}_{\mathrm{b}}\right)$, bending strength $\left(\sigma_{\mathrm{b}}\right)$, and maximal bending strain $\left(\varepsilon_{\mathrm{b}}\right)$.

(b)
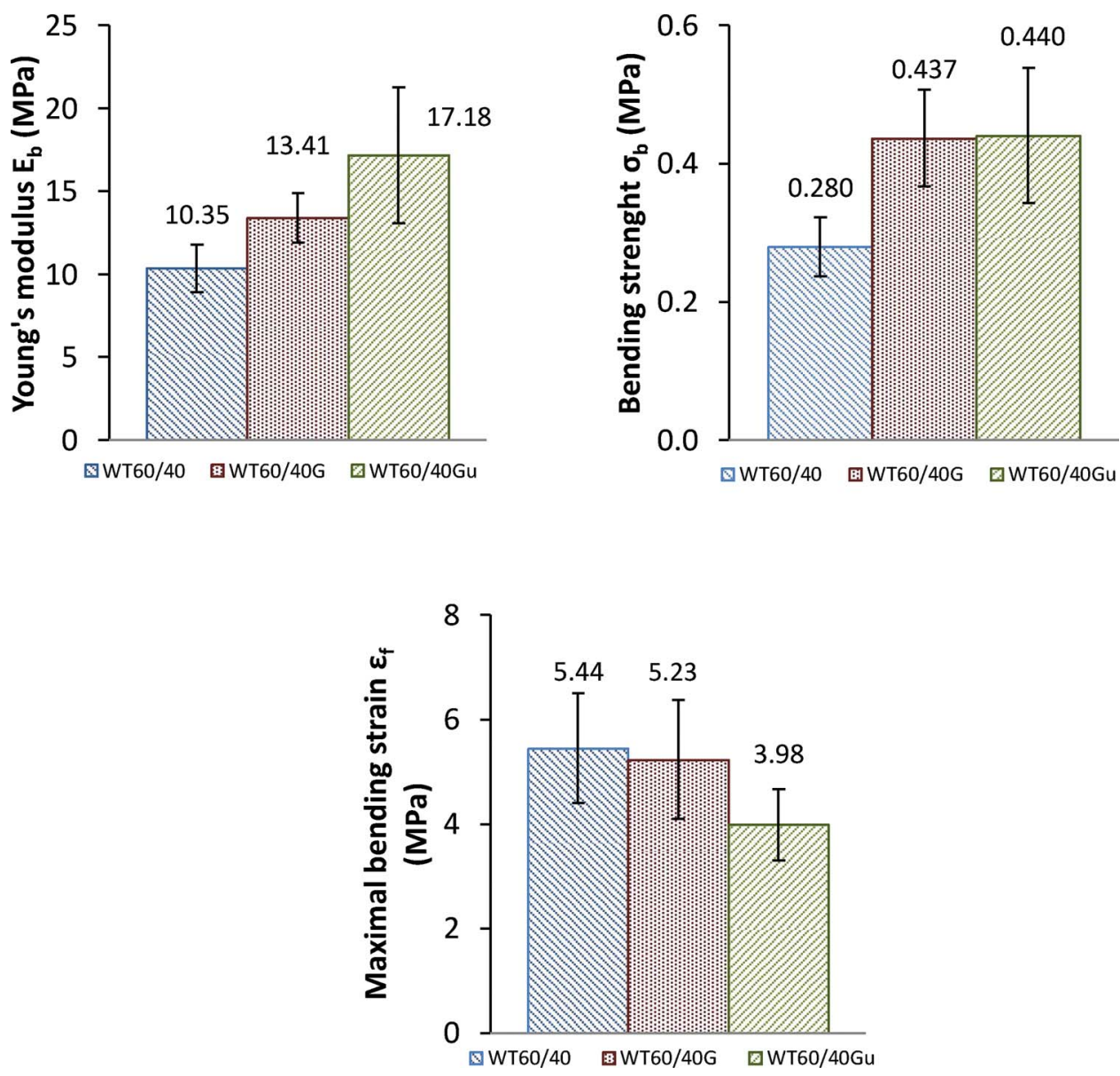

the presence of a crosslinking agent seems to accelerate the drying process. Glyoxal seems to be more effective than glutaraldehyde that could be related to the higher reactivity as demonstrated by DSC experiments.

\subsubsection{Thermal properties}

Table 2 relates conductivity, effusivity, diffusivity, phase difference and thermal capacity values according to the wood fiber content or to the density. As a reference, thermal properties of wood fibers and of recycled cotton fibers were also measured and reported in Table 2.

First of all, considering that a material is qualified as insulating when its conductivity is less than $0.1 \mathrm{~W} / \mathrm{m} / \mathrm{K}$ (Jelle, 2011), alginate based biocomposites of this study can be considered as insulators with thermal conductivities included between 0.078 and $0.089 \mathrm{~W} / \mathrm{m} / \mathrm{K}$. In comparison with other building insulation materials in the same range of density (300-350 kg/m $\mathrm{m}^{3}$ ), like it can be the case of lightweight concretes with natural aggregate (hemp or rice husk), alginate based biocomposites have challenging insulation properties (Chabannes, 
(a)

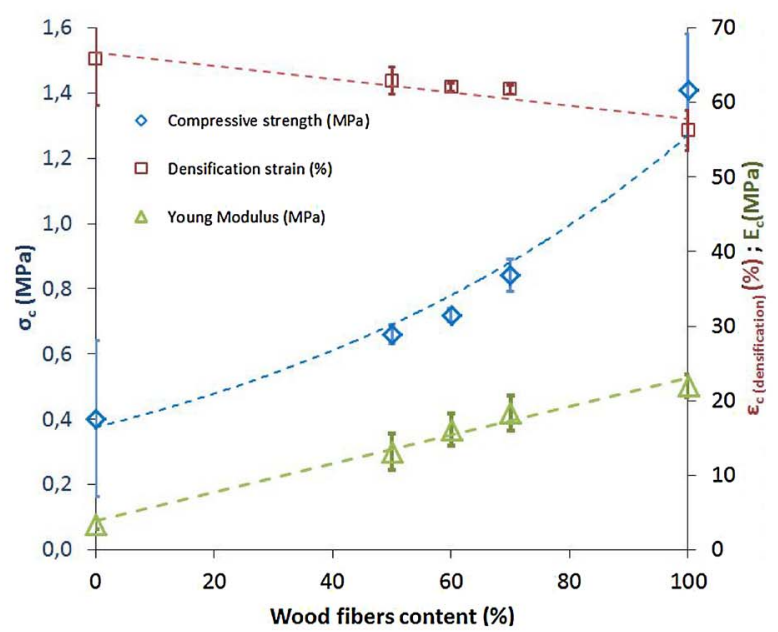

(b)
Fig. 6. Compressive properties (a) of alginate-based composites as a function of the wood fibers contents and (b) of WT60/40 alginate-based biocomposites with different crosslinking agents: Young's modulus $\left(\mathrm{E}_{\mathrm{c}}\right)$, compressive strength $\left(\sigma_{\mathrm{c}}\right)$, and densification strain $\left(\varepsilon_{\mathrm{c}}\right)$.
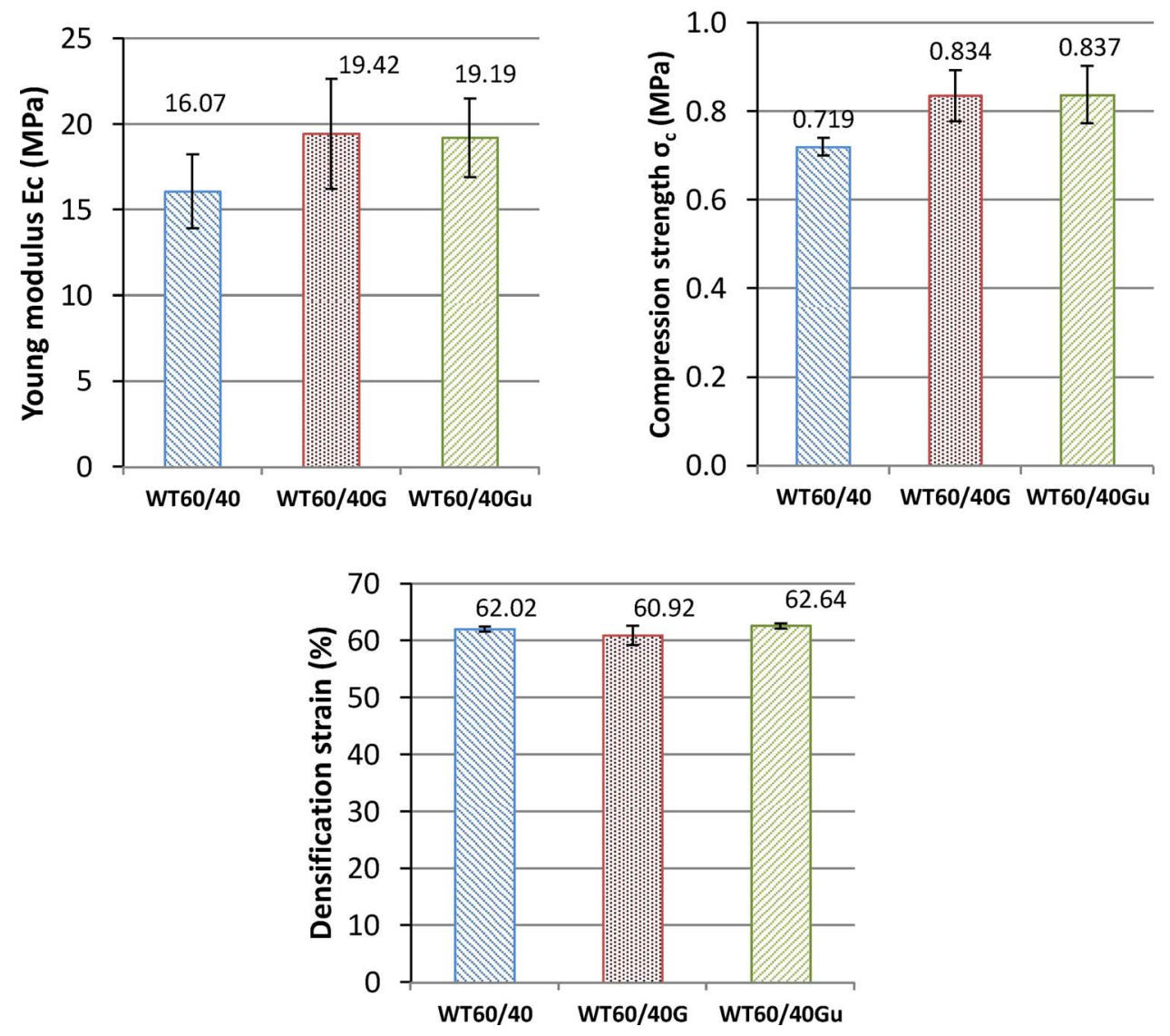

Bénézet, Clerc, \& Garcia Diaz, 2014).

The conductivity is related to the density and the open or closed porosity of the material. Indeed, according to the mechanism of thermal diffusion in porous materials, the more porous the better the insulation. Thus, the conductivity of a porous material is the combination of the conduction of the solid part and the convection of the gas part (air in the present case). For insulation materials, the radiation can be disregarded (Gibson \& Ashby, 1999). The conduction will depend on the chemical nature of the fibers and the binder. The conductivity of sample WT60/40, WT60/40G and WT60/40Gu involves linearly with their densities, meaning that the conduction of alginate binder is slightly affected by the crosslinking. Regarding the conductivities of the recycled cotton and wood fibers, both low-density materials, they have close conductivities of $0.036 \mathrm{~W} / \mathrm{m} / \mathrm{K}$ and $0.040 \mathrm{~W} / \mathrm{m} / \mathrm{K}$ respectively. However, the structure (and then porosity) and the chemical composition of these two fibers are quite different. This specificity leads to a much higher diffusivity of the wood fibers (Table 2), i.e. a better capacity to thermal transfer. Regarding the biocomposites thermal properties, the addition of a higher proportion of wood fibers gives an enhancement of the thermal insulation. On the contrary, the thermal 
effusivity, i.e. the thermal exchange with the environment of the material, decreases with linearly with the quantity of cotton fibers.

It can be also observed that the biocomposites effusivity and diffusivity are increased and decreased respectively in presence of a hardener (Table 2) indicating that they depend mainly on the chemical nature of the solid part. Biocomposites WT60/40G and WT60/40Gu offer low diffusivity and high diffusivity. The thermal capacity, deduced from the effusivity of the material, and the phase difference are consequently higher. So they contribute to an improvement of the thermal comfort of a building envelop.

\subsubsection{Mechanical properties}

4.2.3.1. Bending properties. Fig. 5a represents the different bending properties (strength, maximum strain and modulus) of the alginatebased biocomposites containing different wood fibers/recycled cotton fibers ratios. It can be observed that the rigidity rises linearly with the wood fiber ratio from $3.50( \pm 0.55) \mathrm{MPa}$ to $17.86( \pm 0.84) \mathrm{MPa}$ for WT0/100 and WT100/0 respectively, whereas the densification strain decreases revealing a lowest elasticity of wood fibers compared to waste textile fibers. The bending resistance also depends to the wood fibers ratio: it rises from 0.205 ( \pm 0.001$) \mathrm{MPa}$ to 0.544 ( \pm 0.051$) \mathrm{MPa}$ for WT0/100 and WT100/0 respectively. These results prove that wood fibers give better reinforcement from mechanical point of view and give a higher rigidity to the composite.

The influence of the addition of an aldehyde used as a crosslinker for alginate solutions was studied for WT60/40 biocomposites (Fig. 5b). The bending Young's modulus of WT60/40 biocomposite was measured at $10.35( \pm 1.44) \mathrm{MPa}$. This rigidity was significantly increased with the addition of a hardener such as glyoxal $\left(\mathrm{E}_{\mathrm{b}}=13.41( \pm 1.5) \mathrm{MPa}\right.$, i.e. $+26 \%)$ or glutaraldehyde $\left(\mathrm{E}_{\mathrm{b}}=17.18( \pm 4.1) \mathrm{MPa}\right.$, i.e. $\left.+66 \%\right)$. Thus, the bending resistance was also improved with the presence of hardener and was measured at $0.437( \pm 0.070) \mathrm{MPa}(+56 \%)$ and $0.440( \pm 0.098) \mathrm{MPa}(+57 \%)$ with glyoxal and with glutaraldehyde respectively compared to 0.280 ( \pm 0.043 ) MPa for composite without hardener. The reduction of the maximal bending stress also indicated the more important rigidity of the samples in the presence of an aldehyde-based crosslinker.

4.2.3.2. Compression tests. The properties of composites with different wood fibers contents tested under compression are reported in Fig. 6a. Similar trends to bending solicitation were obtained. Young's modulus in compression increased linearly with the wood fiber content from 3.38 ( \pm 0.65) MPa for WT100/0 to 21.98 ( \pm 1.60 ) MPa for WT0/100. The compression resistance increases from $0.402( \pm 0.240) \mathrm{MPa}$ to 1.410 ( \pm 0.170) MPa for WT0/100 and WT100/0 respectively. These results highlight the difference in the mechanical properties of the composites for different loading conditions, which proved to be stronger in compression than in bending. It allows assuming that the tensile stresses induced by the bending deformation are less borne by these composites than compressive stresses.

Fig. 6b describes mechanical properties under compression of WT60/40 biocomposites depending on the crosslinking agent used. A $20 \%$ increase in rigidity and $16 \%$ increase in compression strength were observed for the WT60/40G and WT60/40Gu biocomposites compared to WT60/40. No significant difference according to the hardener nature was observed. The densification strain is not significantly modified ranging about $60 \%$.

These results confirm the improvement of the mechanical performance under compression of the aforementioned biocomposites but the effect of the formation of a polymeric branched network due to the crosslink agent was more significant under bending. Because bending tests induce both compression and tension stresses in the samples, some of the alginate chains are then stretched (rather than compressed) which is likely to highlight the influence of their crosslinking, whereas compression tests does not allow to observe this result.

\section{Conclusion}

Promising biocomposites based on brown algae polysaccharide binder, namely sodium alginate, were manufactured. These biocomposites have a thermal conductivity around $0.08 \mathrm{~W} / \mathrm{m} / \mathrm{K}$, changing linearly with the density of the composite. Wood fibers are better insulation reinforcement. These composites are semi-rigid according to their mechanical properties: compression strength between 0.40-1.41 MPa and bending strength between 0.20-0.54 MPa for wood fibers content from 0 to $100 \%$. Their densities are around $315 \mathrm{~kg} / \mathrm{m}^{3}$, making them hybrid material between insulation and rigid panels for building envelop. It was seen that the use of recycled cotton fibers gives more plasticity to the material, but on the other hand it was possible to increase the rigidity of the material with the addition of a small amount of crosslinker in the matrix, like $8 \mathrm{w} . \%$ of glyoxal. Finally, alginate appears as a potential candidate for green biopolymer adhesives market.

\section{References}

Asdrubali, F., D’Alessandro, F., \& Schiavoni, S. (2015). A review of unconventional sustainable building insulation materials. Sustainable Materials and Technologies, 4, 1-17. Binici, H., Eken, M., Dolaz, M., Aksogan, O., \& Kara, M. (2014). An environmentally friendly thermal insulation material from sunflower stalk, textile waste and stubble fibres. Construction and Building Materials, 51, 24-33.

Chabannes, M., Bénézet, J. C., Clerc, L., \& Garcia Diaz, E. (2014). Use of raw rice husk as natural aggregate in a lightweight insulating concrete: An innovative application. Construction And Building Materials, 70, 428-438.

Evon, P., Vandenbossche, V., Pontalier, P.-Y., \& Rigal, L. (2014). New thermal insulation fiberboards from cake generated during biorefinery of sunflower whole plant in a twin-screw extruder. Industrial Crops and Productsd, 52, 354-362.

Faruk, S., Bledzki, A. K., Fink, H.-P., \& Sain, M. (2012). Biocomposites reinforced with natural fibers: 2000-2010. Progress in Polymer Science, 37, 1552-1596.

Ghaffar, S. H., \& Fan, M. (2014). Lignin in straw and its application as an adhesive. International Journal of Adhesion and Adhesives, 48, 92-101.

Gibson, L. J., \& Ashby, M. F. (1999). Cellular solids - structure and properties (2nd edition). Cambridge Univ Pr.

Jelle, B. P. (2011). Traditional, state-of-the-art and future thermal building insulation materials and solutions - Properties, requirements and possibilities. Energy and Buildings, 43, 2549-2563.

Kumar, R., Choudhary, V., Mishra, S., Varma, I. K., \& Mattiason, B. (2002). Adhesives and plastics based on soy protein products. Industrial Crops and Products, 16, 155-172.

Lacroix, P., Bergeret, A., Corn, S., Lacoste, C., El Hage, R., 2016. Biocomposite hybride S2P. Patent FR3030538.

La Mantia, F. P., \& Morreale, M. (2011). Green composites: A brief review. Composites Part A, 42, 579-588.

Mati-Baouche, N., De Baynast, H., Lebert, A., Sun, S., Lopez-Mingo, C. J. S., Leclaire, P., et al. (2014). Mechanical, thermal and acoustical characterizations of an insulating bio-based composite made from sunflower stalks particles and chitosan. Industrial Crops and Products, 58, 244-250.

Mookhoek, S. D., Fischer, H. R., \& Van Der Swaag, S. (2012). Alginates fibers containing discrete liquid filled vacuoles for controlled delivery of healing agents in fiber reinforced composites. Composites Part A, 43, 2176-2182.

Nicollin, A., Kueny, R., Toniazzo, L., \& Pizzi, A. (2012). High density biocomposite from natural fibers and tannin resin. Journal of Adhesion Science and Technology, 26, 1537-1545.

Pizzi, A., Scharfetter, H., \& Kes, E. W. (1981). Adhesives and techniques open new possibilities for the wood processing industry. part 1: Experience with tannin based adhesives. Holz als Roh-und Werkstoff, 39, 85-89.

Pizzi, A. (1982). Pine tannin adhesives for particleboard. Holz als Roh-und Werkstoff, 40, 293-301.

Pizzi, A., Kueny, R., Lecoanet, F., 2011. Natural fiber and resin composite material. Patent WO2011/001105A1.

Pizzi, A., Kueny, R., Lecoanet, F., Massetau, B., Carpentier, D., Krebs, A., et al. (2009). High resin content natural matrix-natural fiber biocomposites. Industrial Crops and Products, 30, 235-240.

Quignard, F., Valentin, R., \& Di Renzo, F. (2008). Aerogel material from marine polysaccharides. New Journal of Chemistry, 32, 1300-1310.

Rinaudo, M. (2008). Polyelectrolytes derived from natural polysaccharides. In M. N. Belgacem, \& A. Gandini (Eds.). Monomers, polymers and composites from renewable resources (pp. 495-516). Great Britain: Elsevier.

Yeom, C. K., \& Lee, K.-H. (1998). Characterization of sodium alginate membrane crosslinked with glutaraldehyde in pervaporation separation. Journal of Applied Polymer Science, 67, 209-219.

Zia, K. M., Zia, F., Zuber, M., Rehman, S., \& Ahmad, M. N. (2015). Alginate based polyurethanes: A review of recent advances and perspective. International Journal of Biological Macromolecules, 79, 377-387. 